\title{
Differential Thermal Analysis of Tobacco as a Function of Heating Rate*
}

\author{
by C. O. Tiller and E. M. Gentry \\ Philip Morris Research Center, Richmond, Virginia, U.S.A.
}

\section{INTRODUCTION}

This is an experimental study that examines the thermal decomposition of reconstituted tobacco sheet as a function of the rate of temperature rise when heated. Reconstituted tobacco sheet is a blend of fine particles of tobacco mixed in a slurry and formed into a thin sheet. Physical and chemical changes that occur in a substance when heated, changes that involve the loss or gain of thermal energy, can be detected by differential thermal analysis (DTA). This technique involves measuring the temperature differential between the material of interest and an inert reference, when both are subjected simultaneously to the same heating cycle. The curve obtained for a thermally active substance consists of one or more maxima or minima, representative of endothermic or exorhermic processes.

Thermal analysis techniques have been used by others $(1-7)$ to investigate the decomposition of tobacco, when heated at relatively slow rates $\left(0.08-2.5^{\circ} \mathrm{C} / \mathrm{s}\right)$. They have identified tobacco type, stalk leaf position, the effect of additives, and, recently, the kinetic parameters for the major steps in this complex decomposition. In these latter experiments $R y a n$ (7) has applied the method of Kissinger (8) and determined the reaction order and kinetic parameters for some of these global processes over this limited heating rate range. However, when tobacco is thermally decomposed by smoking of a cigarette, it is estimated that the tobacco particles undergo rates of temperature rise of the order of $50{ }^{\circ} \mathrm{C} / \mathrm{s}$ normally, and at times the rate may be as high as $300^{\circ} \mathrm{C} / \mathrm{s}$. Lilly et al. (9) have assumed that the kinetic processes do not dange at higher heating rates. They have employed a non-linear fitting routine to determine the kinetic parameters for the major events and the thermal shift of events with heating rate. However, theoretical extensions based on studies of slow reactions may not reflect the kinetics of normal decomposition, and it is the purpose of this study to obtain results under realistic conditions.

In the research reported here, DTA curves are recorded for reconstituted tobacco sheet subjected to a wide range of heating rates $\left(0.1-500{ }^{\circ} \mathrm{C} / \mathrm{s}\right)$. Using first-order kinetic relationships, the kinetic parameters are found and compared with values for tobacco leaf and cellulose decomposition.

- Received for publication: 2nd August, 1976.

\section{EXPERIMENTAL}

Samples of reconstituted tobacco sheet, $0.48 \mathrm{~cm}$ square and $0.015 \mathrm{~cm}$ thick, are heated in flowing $\mathrm{He}$ at a rate in the range $0.1-500^{\circ} \mathrm{C} / \mathrm{s}$ in an adaption of the thinfoil calorimeter described by Hager (10). In this calorimeter the thin-foil heater is folded in an accordion-like arrangement with the sample and its thermocouple, and the reference and its thermocouple, compressed in adjacent pleats near the center of the heater. The reference material is either mica or tobacco char. Tobacco char, in this instance, is the carbonaceous residue remaining after tobacco is heated slowly to $600^{\circ} \mathrm{C}$ in a $\mathrm{He}$ atmosphere. The thermocouples are $3 \mathrm{mil}$ diameter chromel-alumel, which are embedded in the reference material or compressed between two sheets of tobacco sample.

Power for the heater is supplied by a Hewlett-Packard model 6269 B direct current power supply adjusted to operate in the constant current mode. The electromotive force generated by the reference thermocouple is amplified by a Keithley model 610 B electrometer, and applied through a voltage divider to one channel of a Honeywell model $906 \mathrm{~A}$ multichannel visicorder. The differential electromotive force between the reference and sample thermocouples is amplified by a Princeton Applied Research model 113 pre-amplifier and applied through another voltage divider to a separate channel of the recorder.

After thermal equilibrium is established with the sample in position, the amplifier recorder system is zeroed. The current level, corresponding to the desired average heating rate, $\vec{b}$, is then set on the meter of the power supply, which has its output short-circuited. The dhartspeed is chosen and the recorder is started. Recording of the reference temperature, $T_{R}$, and the differential temperature, $\Delta T$, versus time is commenced when the short circuit is removed, and is ended when $T_{R}$ has traversed the temperature range of interest. When the newly darred sample cools to room temperature, it is heated again at the same rate, and a second, background, recording obtained.

After subtracting the background algebraically from the original recording to remove baseline drift and spurious results due to the apparatus (11), the data is replotted as $\Delta T$ versus $T_{R}$ for ease of analysis. Of the several characteristic temperatures that are identifiable from the DTA curves, the results of these experiments are analyzed 
Figure 1. DTA curves for reconstltuted tobacco sheet Illustrating the shift of reaction temperatures with an Increase of heating rate.

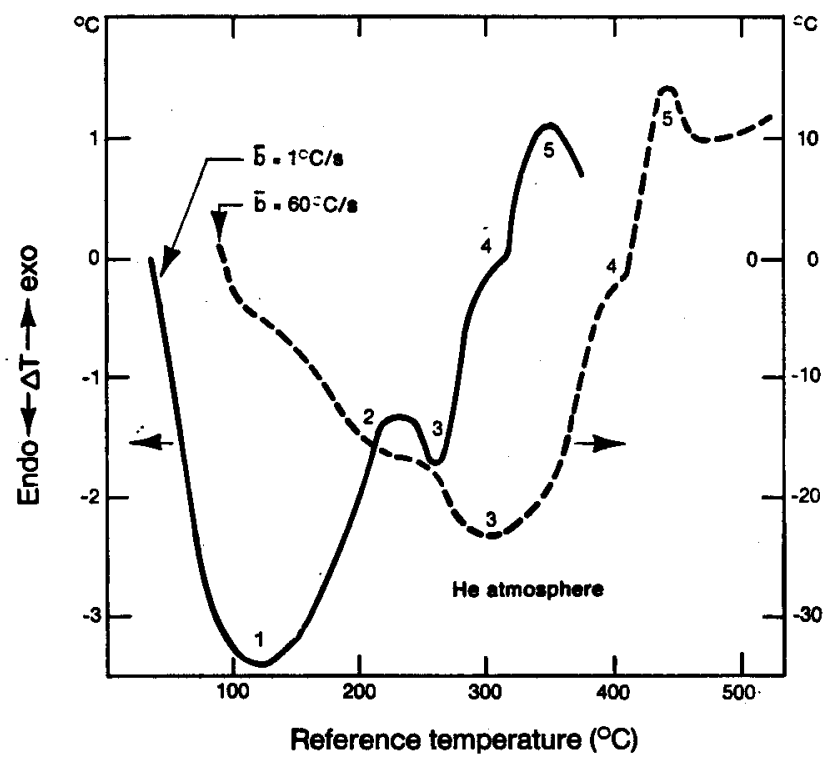

Figure 2. DTA curves Illustrating the effects of adding KNO, to $\alpha$-cellulose.

-..$-: \quad \alpha$-cellulose

---- : $\mathrm{KNO}_{3}$

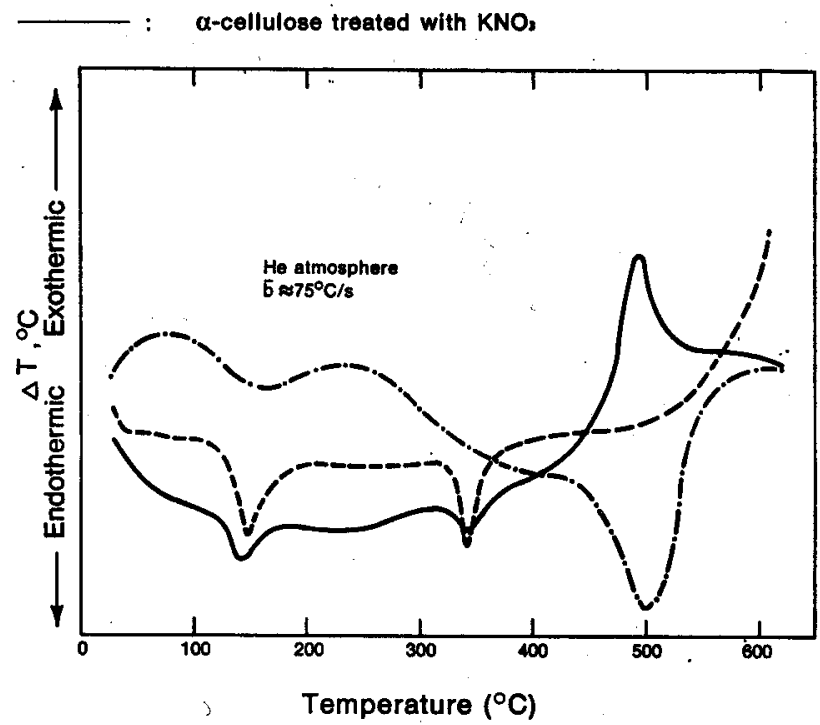

Figure 3. Characteristic temperatures as a function of heating rate.

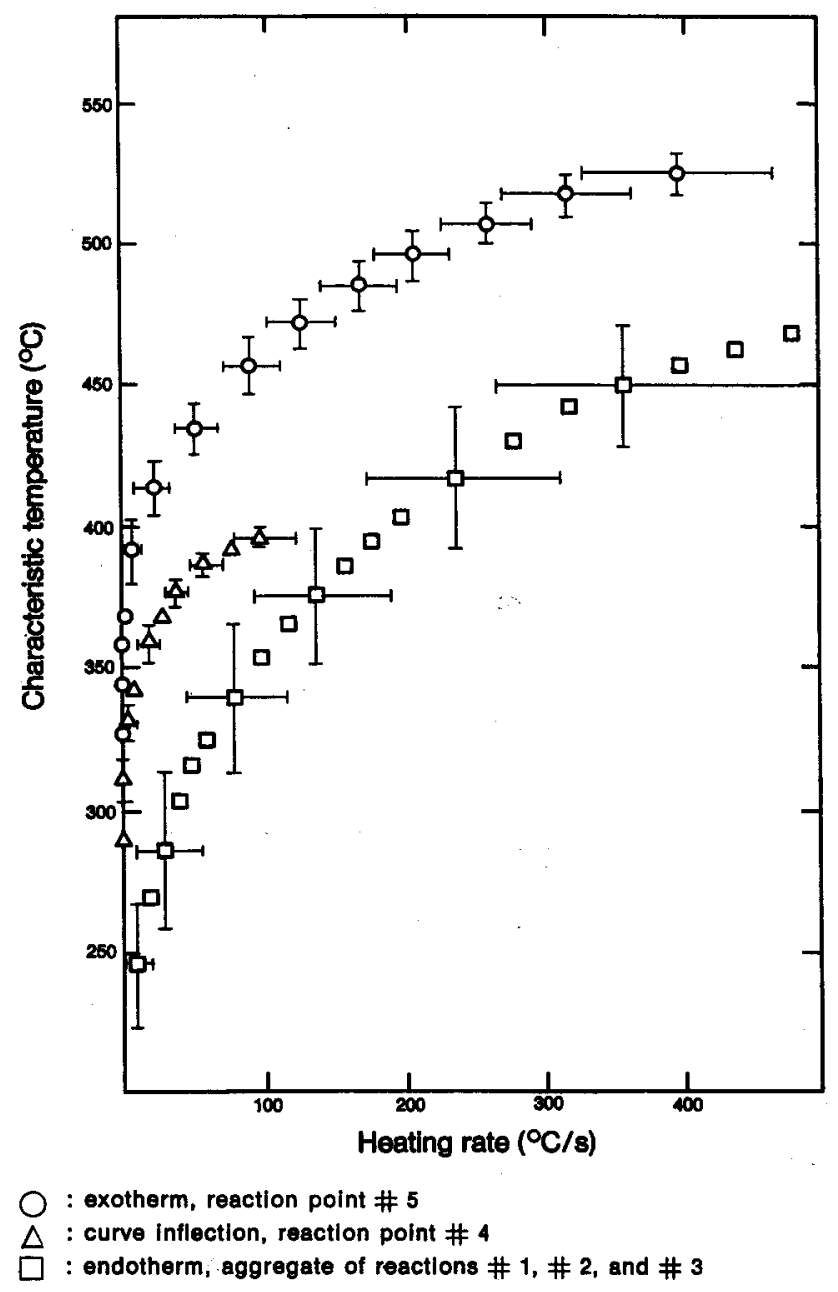


in most cases in terms of the reference temperature associated with a maximum or minimum in $\Delta T, T_{m}$, for an endothermic or exothermic reaction.

With the experimental method employed the heating rate is not constant over the heating cycle, but decreases as the temperature is increased. Because of this variation the data has been analyzed using the instantaneous heating rate, $b_{i}$, at the reference temperature of interest.

The reliability of the temperature measurements obtained under operating conditions was verified using National Bureau of Standards DTA Temperature Standards No. 758.

\section{RESULTS AND DISCUSSION}

\section{Differential Thermal Analysis (DTA) Curves}

The DTA curves for reconstituted tobacco sheet (Figure 1) are similar in appearance to those obtained for ground tobacco leaves $(1,3)$ and a ground tobacco blend (7) when heated in a nitrogen atmosphere. Generally, at all heating rates, there is a rather large endothermic envelope followed by a subdued exothermic region. The inflection, \# 4, in the curve separating the endothermic from the exothermic region has been noted by others $(3,5,7)$ and is associated with a sudden weight loss in thermogravimetric measurements $(3,7)$. Four or five major thermal events (dependent on the type of tobacco) have been recorded in the literature for low heating rates and the characteristic temperatures are compared at a heating rate of $0.167{ }^{\circ} \mathrm{C} / \mathrm{s}$ with the present results in Table 1 . The present work agrees well with previous data except that $E d m o n d s$ et al. (1) found the first endotherm at a much lower temperature than other workers and also identified the inflection as an endotherm. Endotherm \# 2 is observed in the curve (Figure 1) for a heating rate of $60^{\circ} \mathrm{C} / \mathrm{s}$, but, if present for a heating rate of $1^{\circ} \mathrm{C} / \mathrm{s}$, is hidden in the background of the large endothermic envelope.

These thermal events may be associated with the process by which cellulosic materials degrade $(12,13)$. Endotherm \# 1 is attributed to the vaporization of highly volatile materials such as extra-cellulosic water and low-

Table 1. DTA characteristlc temperature comparison for tobacco samples heated in an Inert gas atmosphere at a rate of $0.167^{\circ} \mathrm{C} / 8$.

\begin{tabular}{|c|c|c|c|c|c|}
\hline & $\begin{array}{c}\text { Endo- } \\
\text { therm } \\
\# 1 \\
\left({ }^{\circ} \mathrm{C}\right)\end{array}$ & $\begin{array}{c}\text { Endo- } \\
\text { therm } \\
\# 2 \\
\left({ }^{\circ} \mathrm{C}\right)\end{array}$ & $\begin{array}{l}\text { Endo- } \\
\text { therm } \\
\# 3 \\
\left({ }^{\circ} \mathrm{C}\right)\end{array}$ & $\begin{array}{c}\text { Inflec- } \\
\text { tion } \\
\left({ }^{\circ} \mathrm{C}\right)\end{array}$ & $\begin{array}{l}\text { Exo- } \\
\text { therm } \\
\left({ }^{\circ} \mathrm{C}\right)\end{array}$ \\
\hline Edmonds et al. (1) & 70 & 169 & - & $268 *$ & 324 \\
\hline $\begin{array}{l}\text { Yamashita and } \\
\text { Kobayashi }(2,3,4)\end{array}$ & 120 & 180 & 230 & 265 & 305 \\
\hline Ryan (7) & 124 & - & 226 & 261 & 319 \\
\hline This Research & 117 & - & 228 & 268 & 325 \\
\hline
\end{tabular}

* Edmonds et al. identifled the event as an endotherm. boiling compounds. Using thermogravimetric analysis Burton and Burdick (5) found that below $210^{\circ} \mathrm{C}$ fluecured and Oriental tobaccos exhibited the greater weight losses, when compared with Burley and Maryland, and it is significant that these tobaccos are also higher in amount of reducing sugars (14). By comparison it is assumed that endotherm \#2 is partially the result of degradation of these sugars. Endotherm \# 3 is related to the evolution of bound water to form a "dehydrocellulose", pyrolytic decomposition of carbohydrates such as starch, and vaporization of less volatile compounds. The thermal decomposition of starch is reported to proceed rapidly at about $220-230^{\circ} \mathrm{C}(15)$.

It is generally agreed that there are at least two basic and competitive modes of decomposition for cellulosic and cellulose-like materials above $250{ }^{\circ} \mathrm{C}$. The first mode is a depolymerization of cellulose to 1,6-anhydro$\beta$-D-glucopyranose (levoglucosan), which is the major fraction of the tar formed and, therefore, is called the tar forming mode. Madorsky et al. (16) suggest that this is the result of random scission of the 1,4-glycosidic linkages. As mentioned previously, by comparison with thermogravimetric results $(3,7)$ this first mode is identified by a sudden weight loss at $\sim 270^{\circ} \mathrm{C}$ and this corresponds to the inflection in the DTA curve at $268^{\circ} \mathrm{C}$.

The second mode of degradation is often called the char forming mode, and is the result of more drastic changes in the molecular structure. It is the result of ring scission or extensive elimination of the residual hydroxyl groups of the intact glucosan units of the cellulose molecule. This degradation is endothermic in an inert atmosphere and exothermic in an oxygen atmosphere as demonstrated by others (17). In contrast, it is observed with the tobacco samples investigated here that this process is exothermic in a $\mathrm{He}$ atmosphere, even though it has been noted that cellulose extracted from tobacco degrades by an endothermic process. An explanation of this may be found in the many additional compounds available for thermal reaction in tobacco. These compounds may supply oxygen for combustion (18) or constituents which act as catalyst for the exothermic process. Mineral salts, such as $\mathrm{KNO}_{3}, \mathrm{NaNO}_{3}, \mathrm{Ca}\left(\mathrm{NO}_{3}\right)_{2}$, etc., are present in tobacco in sufficient quantities to fulfil these speculations, and alteration of the reactions by the addition or removal of these salts has been noted, as illustrated in Figure 2. In this figure the addition of $\mathrm{KNO}_{3}$ to $\alpha$-cellulose converts the normal endothermic process to an exothermic one.

\section{Effect of Heating Rate}

As the heating rate is increased, the global processes (19) of decomposition shift to higher temperatures, and the various pyrolytic reactions tend to overlap, or coalesce, as discussed by Wendlandt (20) and Mackenzie and Mitchell (21). Resolution of the different events becomes more difficult as the heating rate is increased, but, even so, it has been possible to follow this shift for the exotherm (\#5), the inflection point (\#4), and the average of the three endotherms (\#1,2, and 3) as shown in Figure 3. These curves are the results of averaging many 
experiments, and error bars are shown on some of the plotted points to indicate the range. Displacement of the envelope for the endothermic peaks is greater as a function of rate than for the exothermic peak, and, as a consequence of superposition, the curve inflection, \# 4, is lost for heating rates above $\sim 100{ }^{\circ} \mathrm{C} / \mathrm{s}$. Another result of superimposing the small exothermic and large endothermic peaks is that the characteristic temperature of the exotherm will be in error at the higher heating rates $\left(>100^{\circ} \mathrm{C} / \mathrm{s}\right)$, since it will appear to be displaced to a higher than normal temperature by this superposition.

\section{Kinetic Parameters}

Kinetic plots for heating rates up to $500{ }^{\circ} \mathrm{C} / \mathrm{s}$ for the average of the three endotherms and up to $100{ }^{\circ} \mathrm{C} / \mathrm{s}$ for the curve inflection and exotherm are presented in Figure 4 as a semilog function of the characteristic temperature squared divided by the heating rate, $T_{m}^{2} / b$, versus the inverse of the characteristic temperature, $1 / T_{m}$. Assuming a first-order kinetic relationship for these bulk processes, the kinetic parameters have been extracted from the slope and intercept of these plots (see Appen$d i x$ ), and are given in Table 2. Since endotherms \# 1, 2, and 3 rapidly coalesce as the heating rate is increased, the values shown in Table 2 for activation energy, $E$, and frequency factor, $k_{0}$, are an average for the sum of

Figure 4. KInetic plots for first-order global processes of reconstltuted tobacco sheet.

0 : exotherm, reaction point \# 5

$\triangle$ : curve inflection, reaction point \# 4

: endotherm, aggregate of reactions \# 1, \# 2, and \# 3

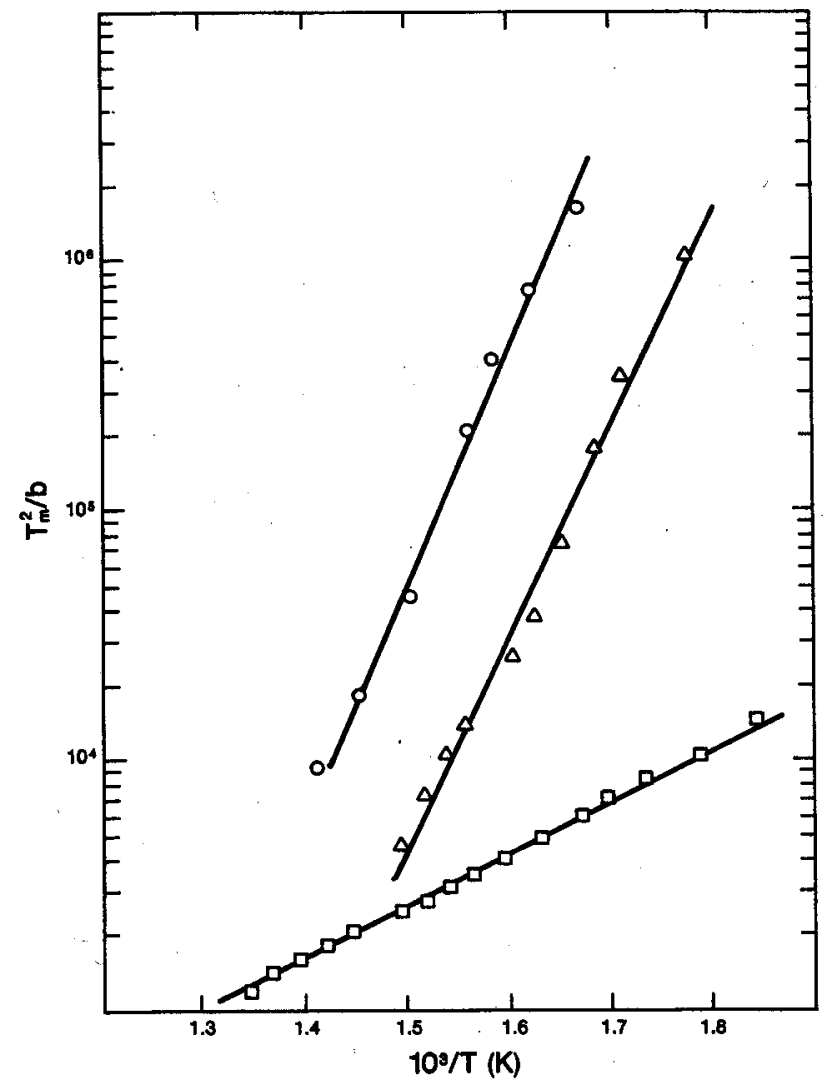

Table 2. KInetic parameters for the thermal degradation of reconstituted tobacco sheet.

\begin{tabular}{lcc} 
& $E(\mathrm{kcal} / \mathrm{mole})$ & $k_{0}\left(\mathrm{~s}^{-1}\right)$ \\
\hline Endotherms (\# 1, 2, and 3) & 9.4 & $2.2 \times 10^{3}$ \\
Curve inflection (\# 4) & 38.7 & $2.2 \times 10^{13}$ \\
Exotherm (\# 5) & 43.0 & $5.8 \times 10^{13}$ \\
\hline
\end{tabular}

these processes. The energy, $9.4 \mathrm{kcal} / \mathrm{mole}$, is suggestive of vaporization of volatile materials and the frequency factor, $2.2 \times 10^{9} / \mathrm{s}$, is indicative of diffusion times in liquids, $10^{-4}$ to $10^{-8}$ s. Lilly et al. (9) have calculated the energy and frequency factors from two low temperature weight loss regions of a differential thermogravimetric curve for a tobacco blend and found them to be $10.2 \mathrm{kcal} / \mathrm{mole}$ and $6 \times 10^{4} / \mathrm{s}$, and $11.6 \mathrm{kcal} / \mathrm{mole}$ and $1.8 \times 10^{3} / \mathrm{s}$, which are in fair agreement with the average value reported here.

The parameters obtained for the exotherm and the thermal event at reaction point \#4 are indicative of decomposition by breakage of a single bond, since the frequency factors, $5.8 \times 10^{13} / \mathrm{s}$ and $2.2 \times 10^{13} / \mathrm{s}$, are in agreement with expected infrared bond vibration frequencies of $10^{13}$ to $1014 / \mathrm{s}$. These parameters compare reasonably with values quoted for tobacco and $\alpha$-cellulose pyrolyzed in a nitrogen atmosphere. Ryan (7) obtained energies for tobacco of $39.6 \mathrm{kcal} / \mathrm{mole}$ and $41.2 \mathrm{kcal} / \mathrm{mole}$ for the differential weight loss peaks assigned to the tar forming and char forming modes. Lipska and Parker (22) using an isothermal technique found a single activation energy of $42 \mathrm{kcal} / \mathrm{mole}$ in the temperature range $250-298{ }^{\circ} \mathrm{C}$ for $\alpha$-cellulose: Nonisothermal techniques at relatively low heating rates $\left(0.004-0.2^{\circ} \mathrm{C} / \mathrm{s}\right)$ were used by Tang and Neill (17) and Akita and Kase (23) to study $\alpha$-cellulose decomposition. Tang and Neill reported an energy of $33.1-35.2 \mathrm{kcal} /$ mole in the initial stage $\left(240-310^{\circ} \mathrm{C}\right)$ of decomposition and $53.1-55.7 \mathrm{kcal} / \mathrm{mole}$ in the final stage $(310-$ $360^{\circ} \mathrm{C}$ ). Akita and Kase found an energy of $53.5 \mathrm{kcal} /$ mole in the range $300-330^{\circ} \mathrm{C}$. Shafizadeb (24) in a study of cellulose decomposition with model compounds found for pyrolysis of $\mathrm{p}$-methoxphenyl- $\beta$ - $D$-glucopyranose an activation energy of $42.8 \pm 1 \mathrm{kcal} / \mathrm{mole}$ by thermogravimetric analysis and $43.9 \mathrm{kcal} / \mathrm{mole}$ by electron spin resonance (ESR) as the energy for cleavage of the glycosidic bond.

\section{CONCLUSIONS}

Based on these results the following conclusions appear justified on the thermal degradation of reconstituted tobacco sheet.

1. The major thermal events occur at approximately the same characteristic temperatures as reported for ground tobacco leaf when pyrolyzed at the same heating rate.

2. When the heating rate is increased, the characteristic temperature for each thermal event is increased, at least 
over the range for which it is observable as a separate event.

3. The kinetics of decomposition are adequately described by a first-order relationship for a heating rate $<100^{\circ} \mathrm{C} / \mathrm{s}$ for all global processes and up to $500{ }^{\circ} \mathrm{C} / \mathrm{s}$ for the average of the endothermic processes. Further, by using the instantaneous heating rate for each thermal event, reasonable values for the kinetic parameters are obtained.

\section{APPENDIX}

The non-isothermal events that occur in the pyrolysis of tobacco are of the type solid $\rightarrow$ solid + gas, and can be described by the equation

$$
\frac{d x}{d t}=k(1-x)^{n},
$$

where $\mathrm{dx} / \mathrm{dt}$ is the reaction rate, $\mathrm{x}$ is the fraction reacted, $\mathrm{n}$ is the empirical order of the reaction, and $\mathrm{k}$ is the specific reaction rate constant. The rate constant is temperature dependent according to the Arrbenius equation

$$
\mathbf{k}=\mathrm{k}_{0} \mathrm{e}^{-\mathrm{E} / \mathrm{R} \mathbf{T}} \text {, }
$$

where $\mathrm{k}_{0}$ is commonly called the frequency factor, $\mathrm{E}$ is the activation energy, $R$ is the universal gas constant, and $\mathrm{T}$ is the absolute temperature. Assuming a first-order reaction and heating rate $(b=d T / d t)$ that is constant, the reaction rate can be shown to be

$$
\frac{d x}{d t}=\left(k_{0} e^{-E / R T}\right)\left(A \exp -\int_{T_{0}}^{T} \frac{k_{0}}{b} e^{-E / R T^{u}} d T^{\prime}\right) .
$$

At a maximum or minimum the derivative of this function is zero,

$$
\frac{d}{d T}(d x / d t)=0
$$

When this operation is performed, it can be shown that

$$
\mathrm{T}_{\mathrm{m}}^{\mathbf{2}} / \mathrm{b}=\left(\mathrm{E} / \mathrm{Rk}_{\mathbf{0}}\right) \mathrm{e}^{\mathrm{E} / R T}
$$

and

$$
\ln \left(T_{m}^{2} / b\right)=\ln \left(E / R k_{0}\right)+(E / R)\left(1 / T_{m}\right)
$$

Therefore, by experimentally determining the characteristic temperature $T_{m}$ as a function of heating rate, the activation energy $E$ and frequency factor $k_{0}$ may be found from the slope and intercept of a ln $\left(T_{m}^{2} / b\right)$ versus $\left(1 / T_{m}\right)$ plot.

\section{SUMMARY}

The differential thermal analysis of reconstituted tobacco sheet heated at rates of $0.1{ }^{\circ} \mathrm{C} / \mathrm{s}$ to $500{ }^{\circ} \mathrm{C} / \mathrm{s}$ in an inert atmosphere is reported. As the heating rate is increased, the characteristic temperature of each global process observed is increased. Using a non-isothermal first-order kinetic equation, the activation energies and frequency factors are obtained for these bulk decomposition processes.

\section{ZUSAMMENFASSUNG}

Es wird über die Differentialthermoanalyse von Folientabak berichtet, welcher in inerter Atmosphäre mit Geschwindigkeiten von $0,1-500{ }^{\circ} \mathrm{C}$ je Sekunde erhitzt wurde. Die für jeden beobachteten Gesamtvorgang charakteristische Temperatur nimmt mit der Erhöhung der Erhitzungsgeschwindigkeit zu. Unter Verwendung einer nichtisothermen kinetischen Gleidhung erster Ordnung ergeben sich die Aktivierungsenergien und Häufigkeitsfaktoren für diese globalen Zersetzungsvorgänge.

\section{RESUME}

L'on présente un rapport sur l'analyse thermique différentielle de tabac reconstitué en feuilles, chauffé dans une atmosphère inerte à raison de $0,1{ }^{\circ} \mathrm{C} / \mathrm{s}$ jusqu'à $500^{\circ} \mathrm{C} / \mathrm{s}$. A mesure que la vitesse d'échauffement est augmentée, la température caractéristique de chaque processus global observé augmente également. En utilisant une équation cinétique non isotherme du premier degré, on obtient les énergies d'activation et les facteurs de fréquence pour ces processus globaux de décomposition.

\section{REFERENCES}

1. Edmonds, M. D., M. T. Core, A. Bavley: Tobacco Sci. 9 (1965) 48-53.

2. Yamashita, Y., and Y. Kobayashi: Sci. Paper, Cent. Res. Inst., Japan Monop. Corp., No. 107, 161-164, 1965.

3. Yamashita, Y., and Y. Kobayashi: Sci. Paper, Cent. Res. Inst., Japan Monop. Corp., No. 108, 211-215, 1966.

4. Yamashita, Y., J. Lee, and Y. Kobashi: Sci. Paper, Cent. Res. Inst., Japan Monop. Corp., No. 109, 125-128, 1967.

5. Burton, H. R., and D. Burdidk: Tobacco Sci. 11 (1967) 180-185.

6. Okada, T., H. Yshibashi, Y. Shimada, and Y. Obi: Tobacco Sci. 12 (1968) 105-106.

7. Ryan, W. S.: to be published.

8. Kissinger, H. E.: J. Res. Natl. Bur. Std. 57 (1956) 217-221.

9. Lilly, A. C., P. Martin, and W. S. Ryan: to be published.

10. Hager, N. E.: Rev. Sci. Instrum. 43 (1972) 11161122.

11. Mitchell, L., and E. C. Henry: J. Am. Ceram. Soc. 26 (1943) 113-119.

12. Kilzer, F. J., and A. Broido: Pyrodynamics 2 (1965) 151-163.

13. Shafizadeh, F.: Advan. Carbohyd. Chem. 23 (1968) 419-474.

14. Tso, T. C.: Encyclopedia of Chem. Technol. 20 (1969) 51.

15. Greenwood, C. T.: Advan. Carbohyd. Chem. 22 (1967) 483-515. 
16. Madorsky, S. L., V. E. Hart, and S. Straus: J. Res. Natl. Bur. Std. 56 (1956) 343-354.

17. Tang, W. K., and W. K. Neill: J. Poly. Sci., Part C, No. 6, 65-81, 1964.

18. Mitchell, B. D.: Scient. Proc. R. Dubl. Soc. A 1, 105-114, 1960.

19. A global process is the apparent process of the assumed major constituents.

20. Wendlandt, W. W.: Thermal methods of analysis; Interscience Publishers, New York, 1964, p. 152.

21. Mackenzie, R. C., and B. D. Mitchell, In: R. C. Madkenzie: Differential thermal analysis; Academic Press, New York, 1970, p. 102.

22. Lipska, A. E., and W. J. Parker: J. Appl. Poly. Sci. 10 (1966) 1439-1453.
23. Akita, K., and M. Kase: J. Poly. Sci., Part A-1, 5, 833-848, 1967.

24. Shafizadeh, F.: J. Poly. Sci., Part C, No. 35, 21-51, 1971.

\section{Acknowledgments}

The autbors are particularly grateful to A. C. Lilly, Jr. for guidance and many constructive comments during the course of this research, $R$. W. Dwyer for aid in the computer analysis of the data, and Dr. D. A. Lowitz for reviewing this paper.

The authors' address:

Pbilip Morris U.S.A., Research Center, P.O. Box 26583, Richmond, Virginia, 23261, U.S.A. 